\title{
National and Cultural Specific Character of Veterinary Terms Motivation in Russian and Kazakh Languages
}

\author{
Beisenova Zhainagul
}

Prof. Dr. Philological Sciences, Kazakh University of Humanities and Law, Astana

Aisada K. Utanova

Kazakh University of Humanities and Law, Astana

Gulnaz S. Imangalieva

Kazakh University of Humanities and Law, Astana, Kazakhstan; Email: zhaina_b@mail.ru

\author{
Doi:10.5901/mjss.2015.v6n5s1p474
}

\section{Abstract}

This article describes specific nature of discipline-specific term motivation in various languages. However, the issue on evolution and development tendencies of special veterinary vocabulary in the Russian and Kazakh languages has not been a subject of special researches and requires scientific description and learning. Veterinary terminology is a set of terms for all directions of the discipline, which conform to the necessary requirements specified to terms. Term motivation is directly analyzed in the article on examples of terms-zoonoses which are characteristic of epizootologic terminology as a branch of veterinary terminology. The cognitive aspect of this terminology presents the peculiarities of system development of special veterinary knowledge that have been formed continuously under the influence of internal and external socio-economic factors. The paper demonstrates the distinctions between the languages caused by distinction of occidental and oriental cultures on examples of untranslatable terms-zoonoses of the Russian and Kazakh languages.

Keywords: term, industry terminology, terminological research, terminological system, modeling the term.

\section{Introduction}

The issue of national and cultural specifics is a traditional one for research in the field of vocabulary, as national features and originality of people's culture are reflected in every language. The national and specific view of the world is formed by special factors, traditions, verbal and nonverbal means. Terminology is a special field of linguistic system that, on the one hand, draws on vocabulary of the native language, on the other hand, is being guided by need of the international contacts of experts in different fields of science, technology and culture, - in an attempt to be international. Epizootologic terms exist in language as a part of the certain, more or less ordered system of the veterinary terminology, and functioning of a separate term is caused by structural and semantic qualities of all terminological system, therefore it is important not only to define the meaning, but also to establish the relation of the term with other lexical units, both special, and common.

The volume of contemporary veterinary terminology is great. The number of secondary microterminological systems connected with the scientific veterinary directions is characterized, in our opinion, by such specific features of their lexical structure, as follows: a) considerable specific weight of the used vocabulary in the structure of terminological system; b) variety of used term sources; c) using of whole fragments of terminological systems; d) an extreme efficiency of compound terms caused by extra linguistic factors. Written veterinary communication occupies a powerful place among other forms of communication.

The description of history of semi-professional and professional "medical treatment" leaves out of limits of several millennia (History of Thycidides, Lucretius "On the nature of things" (98-55 BC), Pliny the Elder "Natural history", Vegetius "Veterinary art or mulomedicine", "Curae boum ex corpore Martialis Gargilli" ("On cattle care from Gargily Martial's work"), Avicenna "Canon of medical science"). The Arabs were the first creators of special medical vocabulary in the East: the works of the greatest Arab philosopher Ibn Sina (Avicenna) in the field of medicine ("Canon of medical science"). Initial formation of bases of medical vocabulary in the European cultural area is connected with the development of Ancient 
Greek medicine (V century BC) and the Ancient Greek language. Seeking for harmonious development of the person, the Greeks along with philosophy and cosmology were also creators of medical science. In Greece, on the Kos islandHippocrates's homeland (460-356 BC) -medicine became the science in contemporary understanding of this word. In the ancient time medicine was considered as high art, and "a good doctor was similar to gods". It is not accidental that the Greeks idolized even some of the people who became famous for unusual art of medical treatment. The son of Apollo, Asclepius who was brought up by a wise centaur Chiron was known as the most skillful doctor allegedly reviving the dead. Being killed by a lightning by Zeus's wish, Asclepius was honored as a "hero" (Hesiod, the end of VIII - the beginning of the VII century BC). Later he was honored as a god of medical treatment. Two of his daughters, Hygeia and Panacea, were also respected as the goddesses of medical treatment.

\section{Lingual and Philosophic Views on the Problem}

Aprioristic reference of peculiar features to special vocabulary of any language is not absolutely indisputable if it is examined in details. In this context the objections from the point of view of intuition and theory can be put forward. The first point of view does not quite clearly explain why such zoonoses as aftosa, smallpox, equinia, strangles in Russian, and in Kazakh oba (plague), manka (equinia), kul'(smallpox), topalan (ulcer) have to identify a certain cultural specificity. To consider the terms-zoonoses in tools of scientific description that do not have operational definitions is inappropriate from the theoretical point of view. But it is necessary to notice that there is a row of non-strict definitions in terminology as, for example, if a term is defined as a uniform, concrete language phenomenon, synonymy, polysemy, homonymy are allowed. Apparently, specific nature of terminology does not allow reaching the formal severity, which corresponds to natural science canons. Nevertheless, the researches of scientific language proves operationalization of used concepts, therefore a feasibility of appealing to categories like national and specific world view of language expressions is obvious.

According to N.Chomsky (1972), linguistic ability involves some congenital and universal meanings, by means of which a person generates and understands a word, and the deepest lines of language structure and semantics, have a natural and genetic basis.

To clarify the nature of a national and cultural component in nosological units of epizootologic terms, it is necessary to identify, first of all, what national and cultural specific nature is.

There are two views on this problem. According to the first, the national and cultural component is identified only in the meaning of so-called words-realia as strangles "disease specific to horses" (to strangle, to clean, - foals strangle in the fourth or fifth year of their life), equinia "disease specific to horses" (to snuffle- a horse snuffled), plague "highly infectious epizootological disease" (plague-stricken), the Kazakh definitions of diseases as akbaypak "cattle plague", zhylan kurt "ascariasis", kempir "plague" (old woman), kum sirke "mange", kobenek "infectious pleuropneumonia". According to this point of view, it is necessary to consider national colored zoonoses as marginal notes that narrow data domain. Inclusion of a maximum wide range of the language phenomena in the concept of national culture is a directly opposed position. This point of view goes back to V. von Humboldt's ideas on internal form of the word and its embodiment in language of "spirit of the people", i.e. we can think about the world only in own "language" circle. In other words, speech communities establish different conceptual views of the world. But, according to the known thesis of G.V. Kolshansky (1990), a conceptual view of the world is only one, because it is created not by one people - a native speaker of any language, but by "mankind as a generation", and the national specifics of a linguistic view of the world - as the specifics of a substance of the material world, but not specifics of a conceptual view of the world. This thought is tracked in the reasonings on a linguistic view of the world of B.A.Serebrennikov (1988). Having distinguished two world viewsconceptual and linguistic - the scientist marks that the conceptual view is wider, richer than a linguistuc view, "conceptual world view has the elements of a community providing mutual understanding of people".

Every national language in its own way divides the world into parts, i.e. has a specific method of its conceptualization. Differently, a special model or a world view lies at the heart of every specific language, and the native speaker is obliged to organize the content of an expression according to this model. When considering the problem of national and specific model of the world, a language role in formation of a world view in the person's conscience, it is necessary to define the concepts conceptual view of the world, linguistic view of the world, as distinction between them is especially brightly shown by comparison of the linguistic phenomena from the point of view of motivation and internal form of the word.

The meaning of expression "world view" can be synonymous to the meaning of expression "set of knowledge about the world". Linguistic views on objective view of the world in knowledge and language explain a world view displayed in consciousness of the person as the secondary existence of the objective world fixed in the peculiar material form. This material form is a language. 
A person introduces to the world not himself, but a special formula "human - world", the result of which is a people's view of the world belonging to all mankind. Subjectivity of this world is defined by accessory to the person. The world, displayed in the ideal form in consciousness of the person, becomes an element of the whole world in the materialized linguistic form.

\section{Term Motivation. Psycholinguistic Approach}

The motivation act for nomination of new objects and phenomena as a linguistic fact of peculiarities of people's searches for the purpose of mastering the subjects depending on specific material living conditions, names of natural phenomena, animal and its diseases give an evident view of infinite variety of phenomena properties mastered by the person. However, it is impossible to tell about a linguistic view of the world separately without its human nature. "As a whole a language does not impose us any perception of the reality, and on the contrary, the reality is unequally reflected in different languages owing to diversity of conditions, mental and public life of people". (Mechkovskay, 1983) Lack of any material objects in a certain society can explain lack of corresponding denotations in the linguistic designation of objects. So, for instance, the motivation specifics of names of animal diseases in the Russian and Kazakh languages proves to the fact of the system of people's choice.

Thus, an attitude of a person to any subject or world phenomenon at a certain stage of knowledge and mastering this world explains a choice of motive of nomination, a method of its description which displays practical use of motivated object. That is, a human factor appears in all linguistic images as every time the person selects and fixes one of the uncountable properties of subjects, phenomena and their communications.

The analysis of mental reality of the person and studies of storing and transmission of human knowledge are regarded as a main activity in the period of so-called "cognitive revolution". E.D. Suleymenova (1998) notes that the contemporary approaches to language and formation of new research paradigms have led to that now in linguistics there are numerous approaches to language, among which the following have a higher priority: ... language and the person ..., language and national mentality ..., language as a cognitive tool, language as a cognitive ability of the person, language as a secondary modulating system".

Contemporary linguistics is under transfer to research of interaction forms of language and thinking integrating experience of such fields of scientific knowledge as psychology, anthropology, etc. The main principles of psycholinguistic researches based on the analysis of linguistic and mental bases of active language skills are very useful in applying terminological motivation.

Disclosure of creative potential of the person in the sphere of motivation of naming subjects and phenomena of surrounding reality mainly demands a psycholinguistic approach, to what the works of domestic and foreign linguists supporting an opinion on different types of transition from thought to the word (B.A.Serebrennikov, Yu.N.Karaulov, N.Zh.Shaymerdenova) testify. From the point of view of psychology information received by a native speaker from the outside world passes a long way, which "along with vigorous activity of sense organs includes both active actions of the people and former experience of generations allowing to go beyond directly received information" (Leontyev, 1976). This creative perception of reality by the person is directly connected with their linguistic and creative activity that gives the chance to regard especially interesting consideration of psycholinguistic bases of motivation of terminological creativity in the field of veterinary medicine, research of a role of associative and figurative thinking of native speakers of the Russian and Kazakh languages in this process.

Capacity of figurative perception of reality helps a person to keep the most essential things in the memory. Memory of a person plays a leading role in preservation of acquired knowledge, labor skills and transfer of accumulated knowledge.

According to N.I. Zhinkin's (1982) opinion denotation is realized as the search of necessary information as fixing it in the memory and as expectation of new achievements in this process.

Selective separation in the linguistic system presented as sign memory will keep only that what develops the progress of the person.

Motivation of the term is a psycholinguistic field. So, the motivated name of animal disease unites two psycholinguistic realities - motivating and motivated concept. The term received thus begins an independent life. The research of fixing process of nomination motive opens associative ways, which connect in consciousness of motivating idea of one subject to idea of other, therefore these images are represented as knowledge of a new word and the terms are created. Yu.D.Apresyan (1969) in his works speaks about semantic association when perceiving a new word. But as the associations in many respects are defined by psychology of an intellectual analyzing the surrounding realities and motivating the observed realities, and the thinking processes of people of different points of the globe are uniform, the 
similar images have been exploited for motivation of terms of veterinary medicine.

\section{Comparison of Veterinary Terms of Russian and Kazakh Languages}

Diseases and parts of body were one of the first and universal phenomena, to which a person compared the studied things. They gave to the people such universal classifications of existing diseases, as infectious and non-infectious, internal and external, mental and physical, intestinal, heart, kidney, gastric, coxofemoral, bone, skin, eye, etc. In the Russian and Kazakh veterinary practice the nomenclature of zoonoses is double: names in Latin, Russian and Kazakh languages are given at the same time. Latin names are equivalent to each other on sounding and peculiar elements. The Russian and Kazakh equivalents represent the Latin name transliterated by the Russian and Kazakh letters without an ending - is.

For instance:

Table 1: Transliteration of the Latin terms-zoonoses in the Russian and Kazakh languages

\begin{tabular}{|l|l|l|}
\hline Latin & Russian & Kazakh \\
\hline Leptospirozis & Лептоспироз & Leptospiroz \\
\hline Candidamycozis & Кандидомико3 & Kandidomikoz \\
\hline Colibacterriozis & Колибактериоз & Kolibakterioz \\
\hline Leucozus & Лейкоз & Leikoz \\
\hline Listeriozis & Листериоз & Listerioz \\
\hline Pasteurellozis & Пастереллез & Pasterellez \\
\hline Salmonellozis & Сальмонеллез & Salmonellez \\
\hline Tuberculozis & Туберкулез & Tuberkulez \\
\hline Grippus & Грипп & Gripp \\
\hline
\end{tabular}

The terms are out of an emotional plan. Therefore metaphoricalness can be used in the terminological nomination of terms-zoonoses for special motivation of the term to display (named phenomena) relations of the named phenomena with each other. For instance, the naming of the same diseases by different nomens depending on a species of an animal tells an originality of natural and informative installations of the people, its creative efforts that creates a peculiar view in naming of the same phenomenon from the various parties in the Kazakh language: "continuum of the world is divided into parts in different world languages differently". It is expressed in that the volume of word meanings in different languages of the world is not identical.

Thus, the linguistic view of the world implements, fixes national and cultural specifics of cogitative activity of a certain society, its mistakes, delusion, national originality, feature of life in a linguistic sign. Nevertheless, all national and specific linguistic views of the world have also the common universal features. A universal semantic component is caused by unity of world view by people of different cultures. This basic unity of human mentality is shown at different levels of semantic organization of language. In the most different cultures a person names the new by means of previously created names narrowing or expanding semantics as it happens to terms.

The community of human psychology brightly develops in the names of animal diseases, for instance, the termzoosis "tetanus" and its Greek equivalent tetanus "hardening", Kazakh "sirespe" (to harden); leukemia, Greek leikos "white", Kazakh ak kan tuiirshikterinin shekten tys kobeui; diarrhea - Greek diarrheo "to run", Kazakh ish otu - to leak; rose though the Polish rose "flower", Kazakh "kyzylsha"; favus "scrofulous rash on the head", Latin Favus - bee's cells"; consumption and its Old Slavic "to disappear", Kazakh kuru; glossitis, from Greek "language", Kazakh tildyn kabynuy; icterus-hepatitis, Greek hepata "liver", Kazakh saryauru "yellow disease" from sargau "to go yellow"; lichen "lacking of relative, Greek $\lambda \varepsilon \mid \varphi \circ \omega I \varepsilon$ "to lose someone's hair", Latin relinguo,-lictus "to leave", etc.

The linguistic national and specific view of the world reflects objective need of existence of a set of world views. There are as many world views as observers contacting to the world and looking at the world through a prism of an individual experience, for instance, of own world view. Quoting the reasoning of B.A.Serebrennikov (1988) that "from the moment of birth we live, we plunge into the world of customs, they are the first and strongest reality that we meet, and they are sensi stricto of our environment or social world, and that society, in which we live. We see people and the world of subjects, we see a universe through this social world or the world of customs". We believe that at a motivation level of structure of a native speaker (in our research - Russian and Kazakh) the national and cultural motivation of linguistic behavior should be considered in connection with its idea of life, and its concrete experience. 
Distinctions between the languages caused by distinction of cultures are noticeable in untranslatable zoonoses of the Russian and Kazakh languages. Many terms of a Greek-Latin origin exist as the borrowed untranslatable special vocabulary. They not only open and interpret foreign culture, but also symbolize it. So, terms-zoonoses strongly entered the terminological system of veterinary science of the Russian and Kazakh languages bronchopneumonia, brucellosis, rhinotracheitis, botulism, cancer, leukosis, dysentery, hepatitis, polyarthritis, abort, flu, gastritis, salmonellosis, furunculosis, stomatitis, ornithosis, typhus, etc. It is possible to judge a share of untranslatable vocabulary in national terminology by such nosological units as:

Russian: plague, hernia, itch, club root disease, yellow sickness, wind, epilepsy, barley, tabes, dead veins, vorogusha fever, diarrhea, St.Anthony's fire, rotting wetness, ice cold fever, eschars, etc.; Kazakh: ak topalan, ylan, ushpa, lan, malik, kotyr, kontek, sary kolka, saktau, delde, kara kaptal, su auruy, katpa, shoshala, korasan, myi kurt, solma, nogala, kuidyrgy, zhamandat, mandam, orken, pishu, sas, sapak saitan sauu, sharana, shemen, shu, alshaktau, ansar, bedeu, borkemyk, bogde auru, burandert-derbez, etc.

In addition when comparing the terms of the Russian and Kazakh languages the revealed lacunas emphasize national and cultural specifics of world view of the peoples. The reasons of appearing lacuna are various. Some lacunas are caused by distinction of cultures of the Russian and Kazakh people - absence of a corresponding denotation in one of compared languages. But this situation not correlated to the names of animal diseases as animals, irrespective of a biotope, are subject to all diseases existing in the world.

Most likely lacunas in terms are caused by the fact that it is unimportant for one language to distinguish what matters in other language.

For instance, one Russian tern-antopozoosis anthrax (Antpax) has ten Kazakh equivalents with its differentiation on properties of the person and pets: tuineme and kuidyrgy (person's), zhamandat (horse's), karatalak (cattle's), akshelek and karabez (camel's), kobenek (goat's), sirespe and kagynu (pig's): Russian smallpox has the following Kazakh equivalents- kul', karasan, sheshek; Russian plague - Kazakh malik, akbaypak, oba; pneumonia - tas okpe, ala okpe; aphthous fever - saryp, ausyl; equinia - manka, sary kolka; covering disease - kara kaptal; trypanosomosis - su-auru, katpa; quarter-evil - karasan, ushayak; mange - kotyr, kontek, kyshyma, kyrshanky; tetanus - sirespe, delbe; ulcer zhauyzdyk, kesel, arambez; fever - bezgek, kyzdyrgysh, etc.

In this case lacunas are caused by distinction of the corresponding cultures. The mentality of the nomadic Kazakh people ennobles and humanizes an animal. Great divisibility of the concepts in the Kazakh zoonoses is caused by the greater importance of animals in social life of the Eastern people than in the Slavic people.

Since ancient times the Kazakhs distinguished four species of animals - tort tulik horse, cow, sheep, camel. A Kazakh word-term mal was usually referred to small species of pets, while in Russian its analog cattle is applicable to all animal species. Relationship of the person and pets, affection to them as to faithful assistants is a historically developed tradition and it has found reflection in fairy tales, eposes, sayings, proverbs. "There are a lot of various stories and legends about the glorified horses: swift-footed Zhelmaya, bozingen - fantastic camels - in short, tort tulik", - M.O. Auezov (1959) writes in the memoirs "Thoughts of different years". In I.Esenberlin's (1986) poetry we find such poetic representation of a horse:

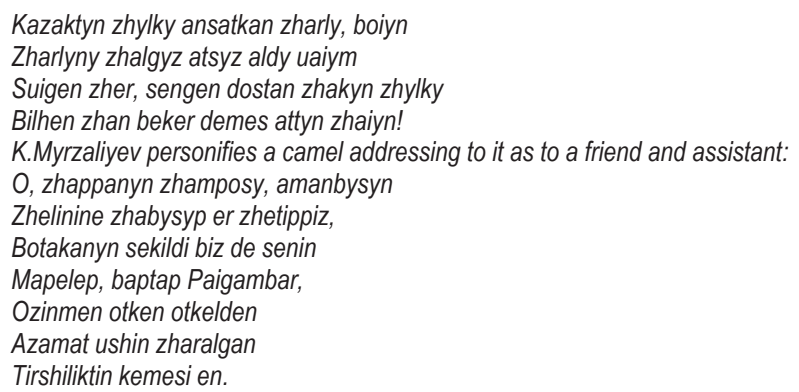

Fixing and etymological interpretation of infectious zoonoses are reflected in the works of M. Auezov (1986), for instance, koksheshek (smallpox, v.VII, p.86), malik (cattle plague, v.VI, p.12), oba (plague, v.VI, p.44,48), saryp (aphthous fever, v.VI, p. 57), sekirtpe (brad sot, v. VII, p. 69). Reflection nature of a continuum of the real world is reflected in medical Oriental philosophy, the symbol of which became "Canon of medical science" by Avicenna (1978) postulating the value of life of animal and people and allocating the Animal as a main model of life, instead of a plant or 
creation. The nomadic people create a constant stock of food - herd. They breed it, preserve, but also depend on it: constantly move behind it in search of new pastures. Such dependence gives rise to feeling of relationship with animals. Hence idolization of animals, especially a horse, is noticed in folklore. A person forms a uniform being with it, a centaur. We find examples of it in the Ancient Greek literature: the wise centaur Chiron brought up by Achill, (775-868) Mutazilit alJahid called his main book "Book on animals".

\section{Conclusion}

Thus, the divergence of the considered terms-zoonoses in the Russian and Kazakh languages tells about different nature of economic activity of the peoples during the pre-revolutionary period of their life: nomadic character of life of the Kazakh people, settled - the Russian people with an agricultural, settled way of life. In a taxonomical mirror of the Kazakh language consecutive differentiation of names of animal diseases in a taxonomical mirror of the Russian language forms blank spaces on semantic "linguistic map" caused by distinction of the corresponding cultures. Untranslatable terms that reflect the culture of the Kazakh people and have no equivalents in Russian are translated only by description. The examples of untranslatable terms described above can be put in one row with the words of general vocabulary as aul, aryk, yurta, in which the Central Asian culture finds its reflection.

Nevertheless, it is impossible to tell that national specific character of motivation of veterinary terms is great and defining. Motivation nature of names does not differ essentially which is caused, in our opinion, by the general features of nominative process of natural nomination, to which considered nominative systems belong. These peculiarities are based on reflective activity of ordinary consciousness of people, on daily human practice, in which there is a general part capable in the conditions of the uniform globe to provide basic unity of their creation that provides motivation unity of objects of the world around.

\section{References}

Apresyan Yu.D. (1969). Interpretation of lexical meanings as a problem of theoretical semantics // AS USSR. - M., Edition 1. - V. 28. pp. 23-55.

Auezov M.O. (1959). Thoughts of different years. - Alma-Ata: Kitap,. - p. 56.

Auezov M.O. (1986). Complete edition. - Alma-Ata, v. 6-7. - pp. 12-86.

Chomsky N. (1972).

Language and thinking. - M.: Nauka Esenberlin I. (1986). Selected works. - Alma-Ata,.. - p. 95.

Fasmer M. (1986-1987).Russian etymological dictionary/Translation from German and amendments by O.N.Trubachev / Edited and with the preface by B.A. Larina. Edition 2, stereotype. - M.: Prosveshenie. - v. 1-4.

Humboldt W. (1984). Selected works on linguistics. - M.,. - pp.71-107.

Ibn Sina. (1978). Canon of medical science. - Tashkent,. - p. 260

Kolshansky T.V. (1990). Objective world view in knowledge and language. - M.: Nauka,.. - p. 21.

Leontyev A.A. (1976). Psycholinguistic aspect of linguistic meaning. Principles and methods of semantic research. - M.: Nauka, - pp. 46-76.

Mechkovskaya N.V. (1983).Language and society // General linguistics. - Minsk,. - p. 118.

Serebrennikov B.A. (1988). Role of a human factor in language // Language and thinking. - M.,.- pp. 8, 118.

Suleymenova E.D. (1998).Some epistemological remarks on language and retrospection // KazNU Journal. Philological issue. - . №18. pp. 80-84.

Zhinkin N.I. (1982). Speech as an information conductor. - M.,. - p. 4. 